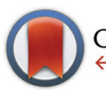

CrossMark \& click for updates

Cite this: Org. Biomol. Chem., 2015, 13, 10527

Received 1st April 2015,

DOI: $10.1039 / c 5 o b 01771 \mathrm{~h}$

www.rsc.org/obc
Accepted 25th August 2015

\section{Synthetic studies on the bioactive tetramic acid JBIR-22 using a late stage Diels-Alder reaction $\dagger$}

\author{
A. R. Healy and N. J. Westwood*
}

A late stage Diels-Alder reaction is used to prepare a mixture of JBIR-22, a natural product from the Equisetin family of tetramic acids, and one of its diastereomers. This is achieved in just 8 steps from pyruvate. The success of the late stage DA approach is discussed in the context of the biosynthesis of JBIR-22 (and perhaps related natural products).

\section{Introduction}

The presence of unsaturated decalin rings in a wide range of secondary metabolites (Fig. 1) has led to the proposal that enzyme-catalysed intramolecular Diels-Alder (IMDA) cycloadditions are involved in the biosynthesis of this unit. ${ }^{1}$ Despite the large number of reports, few enzymes have been discovered which are truly consistent with the label of a
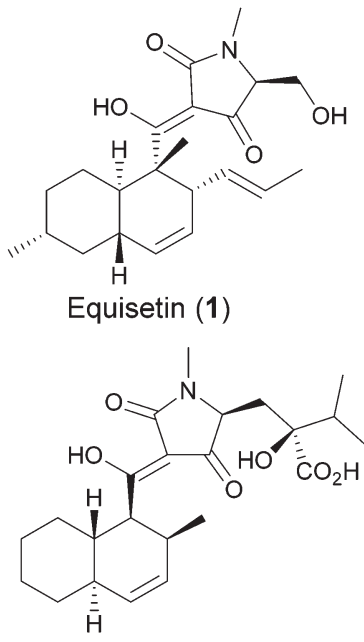

JBIR-22 (3)

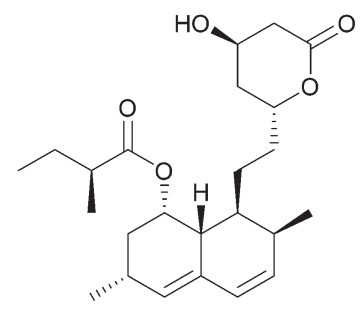

Lovastatin (2)

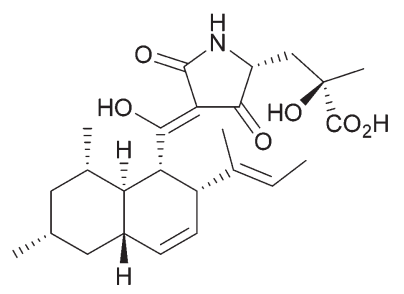

Sch210972 (4) ${ }^{a}$
Fig. 1 Examples of natural products that contain an unsaturated decalin ring system that may be formed by a Diels-Alderase catalysed reaction. ${ }^{a}$ To date only the relative stereochemistry of 4 has been reported.

School of Chemistry \& Biomedical Sciences Research Complex, University of St Andrews \& EaStCHEM, North Haugh, St Andrews, KY16 9ST, UK.

E-mail:njw3@st-andrews.ac.uk

$\dagger$ Electronic supplementary information (ESI) available: UPLC, NMR and all experimental protocols. See DOI: 10.1039/c5ob01771h
"Diels-Alderase" and there remains controversy in several cases. ${ }^{2}$ Key challenges involve demonstrating that an enzyme: (i) catalyses the cycloaddition reaction and (ii) is unambiguously in control of the observed product stereochemistry. ${ }^{2}$ Examples where the stereochemical outcome of the DA reaction differs in the presence or absence of the enzyme provide the most compelling cases for the involvement of a DielsAlderase. ${ }^{2 b, f}$ However, in several cases the product of a proposed enzyme-catalysed DA reaction would be expected to have the same stereochemistry whether the reaction is enzyme- or substrate-controlled (for example see Scheme 1A).

Polyketide or hybrid polyketide-nonribosomal peptide (PKS-NRP) metabolites isolated from bacterial and fungal sources are a rich source of biologically active compounds. ${ }^{3}$ Several of these molecules contain an unsaturated decalin ring system. ${ }^{2 d}$ For example, the HIV-1 integrase inhibitor equisetin (1) is representative of a family of tetramic acid-based natural products of this type (Fig. 1). The complex structure of $\mathbf{1}$ and its potent biological activity has prompted synthetic and biosynthetic studies. ${ }^{4}$ The biosynthesis of equisetin (1) is proposed to involve an early stage enzyme-catalysed IMDA reaction similar to that observed in the biosynthesis of the cholesterol-lowering drug Lovastatin (2) (Fig. 1 and Scheme 1A and B) ${ }^{4 b, 5}$ This is due to similarities in the domain organisation observed for the equisetin (1) PKS-NRP synthase Eqx compared to the lovastatin (2) megasynthetase, LovB. ${ }^{1 a, 2 b, 6}$

Numerous synthetic studies have shown that the presence of the C8-methyl stereocentre ${ }^{4 d}$ in the DA precursor of 1 (Scheme 1A) directs the production of a major endo adduct with the same absolute stereochemistry at C11, C2, C3 and C6 as the natural product $\mathbf{1}$, in the absence of an enzyme. ${ }^{4 d-f, 7-10}$ Recent reports on the isolation, biological evaluation and synthesis of additional members of this family have refocused attention on the DA reaction. ${ }^{11-17}$ For example, the potent PAC3 protein-protein interaction inhibitor, JBIR-22 (3) is of interest in this context as it lacks a C8-stereocentre ${ }^{4 d}$ (Scheme 1C) that could control the formation of the correct 

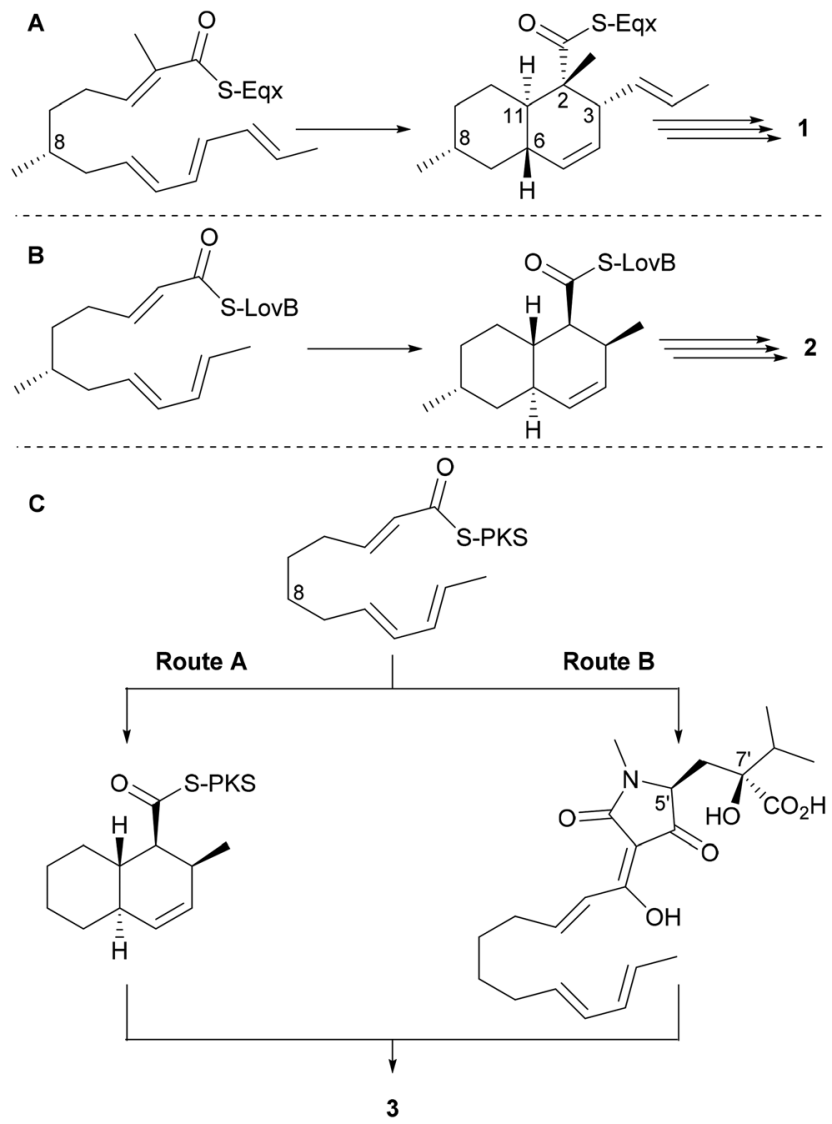

Scheme 1 (A) Proposed biosynthesis of equisetin (1) involving an early stage enzyme-catalysed Diels-Alder (DA) cycloaddition. ${ }^{4 b}$ (B) Proposed biosynthesis of Lovastatin (2) involving the Diels-Alderase LovB. ${ }^{2 b}$ (C) Two possible biosynthetic routes to JBIR-22 (3). Route A: Early stage DA cycloaddition which would require enzyme catalysis to control the stereochemical outcome. Route B: Late stage DA cycloaddition which could occur spontaneously under substrate control or occur via enzyme catalysis. For clarity the numbering system used reflects that reported for equisetin (1) in ref. $4 d$. PKS = polyketide synthase.

absolute stereochemistry in the decalin unit. Given all this, it is possible that an enzyme-controlled DA reaction is involved in the biosynthesis of JBIR-22 (3).

Determining whether a Diels-Alderase is actually involved in a biosynthetic sequence to 3 requires extensive studies beyond the scope of this report. However, an interesting question relating to the timing of the required DA reaction can be addressed through synthetic studies with the issue being whether this reaction can occur early (Scheme 1C, Route A as for lovastatin (2)) or late (Scheme 1C, Route B). Whilst current opinion sides with an early DA reaction, the feasibility of a late stage DA reaction is understudied. ${ }^{1 a, d, 2 f} \mathrm{~A}$ recent disclosure involving the structurally-related HIV inhibitor Sch210972 (4) (Fig. 1 \& Scheme S1 $\dagger$ ) supports the feasibility of a late stage DA. ${ }^{18,2 f}$ Here we provide evidence that whilst a spontaneous late stage DA reaction does not lead to JBIR-22 (3) in the lab, with a suitable catalyst, this late stage DA reaction is possible and in the absence of additional stereocontrol, results in the formation of an equimolar mixture of two endo diastereomers. To the best of our knowledge JBIR-22 (3) exists, as a single diastereomer, so our studies suggest that if a late stage DA reaction is used to prepare JBIR-22 (3) in nature, an asymmetric catalyst is required, consistent with recent studies on $4 .{ }^{18}$

To investigate the feasibility of a late stage DA reaction, a concise synthesis of the precursor $\mathbf{5}$ was developed. This used our reported lactone $\mathbf{6}$, which was prepared in 3 steps from pyruvate via a $\mathrm{N}$-tert-butylsulfinyl-directed aldol condensation. ${ }^{13,15}$ Removal of the $N$-sulfinyl group and diastereoselective reduction gave 7 which was trapped with the phosphonate-containing Meldrum's acid derivative 8 to provide 9 (Scheme 2). A one-pot cyclisation and Horner-Wadsworth-Emmons olefination with known aldehyde $10^{13,19}$ gave the precursor 5 in an efficient 6 steps (34\% yield). ${ }^{20}$ With 5 in hand, we aimed to investigate if a late-stage IMDA cycloaddition was (i) viable ${ }^{21}$ and (ii) able to establish the required absolute configuration at the decalin stereogenic centres.

No significant reaction of $\mathbf{5}$ was observed in toluene when heated to $130^{\circ} \mathrm{C}$ under microwave conditions over 1 hour or in $\mathrm{CDCl}_{3}$ at $50^{\circ} \mathrm{C}$ for 6 days (Table 1, entries $1 \& 2$ ). The DA reaction did proceed in toluene at reflux over 6 days but did not go to completion. However, the Lewis acid $\mathrm{BF}_{3} \cdot \mathrm{OEt}_{2}$ catalysed the reaction of 5 with complete conversion being observed after 12 hours $\left(-78{ }^{\circ} \mathrm{C} \rightarrow \mathrm{rt}\right.$, entry 3$)$. The stereochemical outcome of this transformation was assessed by UPLC following hydrolysis of the crude reaction mixture. An authentic mixture of diastereomers $\mathbf{3 a}$ and $\mathbf{3 b}$ was used as a standard. ${ }^{22}$ Analysis

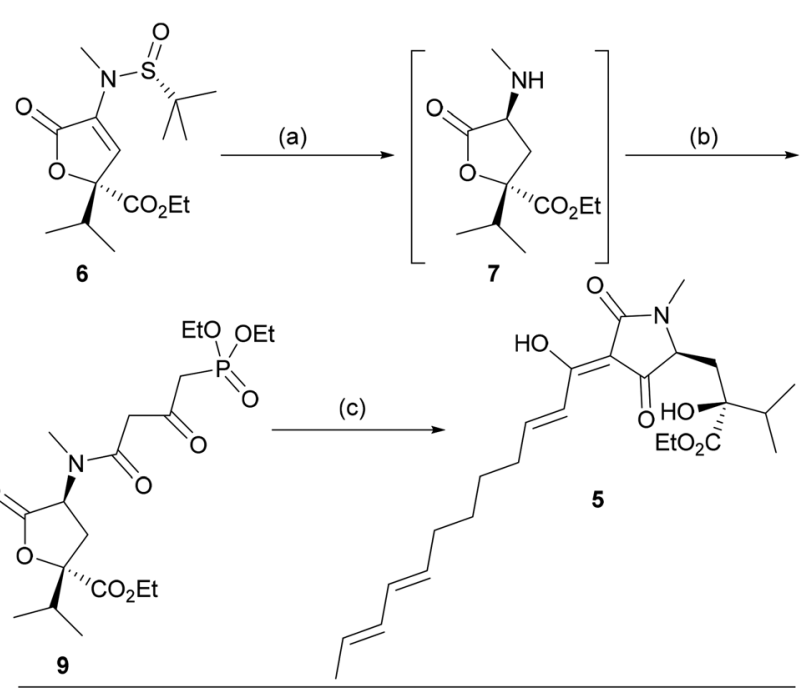<smiles>CCOP(=O)(CC(O)=C1C(=O)OC(C)(C)OC1=O)OCC</smiles>

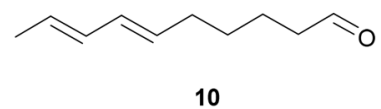

8

Scheme 2 Synthesis of IMDA precursor 5. (a) (i) $\mathrm{HCl}$ (4N in dioxane), THF, $0{ }^{\circ} \mathrm{C}, 10$ minutes. (ii) $\mathrm{NaBH}_{3} \mathrm{CN}, \mathrm{MeOH}, 1.5$ hours, $0{ }^{\circ} \mathrm{C}$; (b) 8 , $\mathrm{MeCN}$, reflux, 3 hours, $79 \%$ over 2 steps; (c) (i) ${ }^{\mathrm{t}} \mathrm{BuOK}, \mathrm{THF}, 0{ }^{\circ} \mathrm{C}, 1$ hour. (ii) $10, \mathrm{THF}, 0{ }^{\circ} \mathrm{C} \rightarrow \mathrm{rt}, 12$ hours, $85 \%$. For a more detailed discussion of the conversion of 9 to 5 see Scheme S2. $\dagger$ 
Table 1 A selection of the conditions screened to promote the IMDA cyclisation of 5

\begin{tabular}{lllll}
\hline & Catalyst/temperature & Solvent & Time & $\begin{array}{l}\text { Selectivity } \\
(\mathbf{3 a}: \mathbf{3 b})\end{array}$ \\
\hline 1 & $130^{\circ} \mathrm{C}$ & Toluene $^{\circ}$ & $1 \mathrm{~h}^{a}$ & $\mathrm{NR}$ \\
2 & $50^{\circ} \mathrm{C}$ & $\mathrm{CDCl}_{3}$ & $6 \mathrm{~d}$ & $\mathrm{NR}$ \\
3 & $\mathrm{BF}_{3} \cdot \mathrm{OEt}_{2}\left(-78{ }^{\circ} \mathrm{C} \rightarrow \mathrm{rt}\right)$ & $\mathrm{DCM}$ & $12 \mathrm{~h}$ & $53: 47^{b, c}$ \\
4 & $\mathrm{Mg}^{b-b i s o x a z o l i n e ~(12)}$ & DCM & $12 \mathrm{~h}$ & $61: 39^{b, c, d}$ \\
& $\left(-78^{\circ} \mathrm{C} \rightarrow \mathrm{rt}\right)$ & & &
\end{tabular}

${ }^{a}$ Microwave reaction. Extended reflux (6 days) in toluene led to partial conversion (data not shown). ${ }^{b} \mathbf{3 a}: \mathbf{3} \mathbf{b}$ ratios are an average of 3 samples run in duplicate. ${ }^{c}$ ESI for UPLC traces. ${ }^{d} 20$ mol\% of 12 was used.

revealed that $\mathbf{a} \sim 1: 1$ mixture of diastereomers $\mathbf{3} \mathbf{a}$ and $\mathbf{3 b}$ was formed (no major additional peaks were observed on analysis of the crude reaction mixture). This demonstrated that whilst the DA cycloaddition occurred with high endo selectivity, ${ }^{23}$ no significant control of the absolute configuration at C11, C2, C3 and $\mathrm{C} 6$ was induced by the remote $\mathrm{C}^{\prime}$ and $\mathrm{C}^{\prime}$ stereocentres ${ }^{4 d}$ (Scheme 1A and C). These results are consistent with the possibility that JBIR-22 (3) could be formed by a catalysed late stage IMDA reaction which requires an additional source of stereocontrol to deliver the observed absolute stereochemistry. Further detailed biochemical studies are required to identify if an enzyme is involved and to validate at what stage the decalin ring is formed.

Finally, preliminary attempts to enrich for the formation of either $\mathbf{3 a}$ or $\mathbf{3 b}$ using an asymmetric catalyst were carried out (Scheme 3). C2-symmetric metal-ligand complexes have been

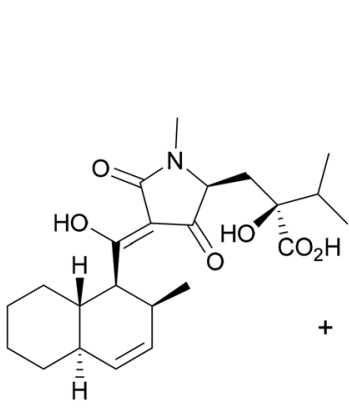

$3 a$

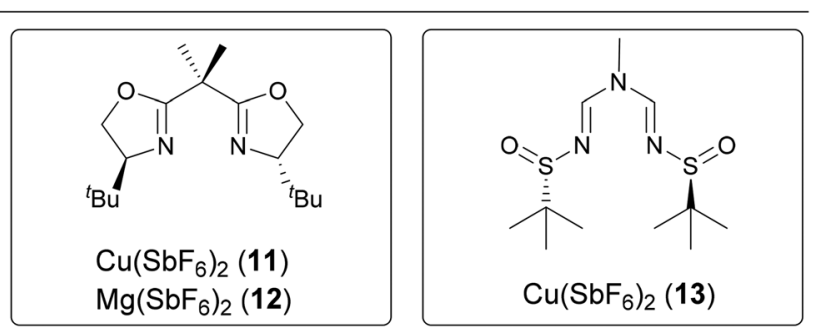

Scheme 3 IMDA cyclisation of 5 followed by hydrolysis to yield diastereomeric mixture of $3 a$ and $3 b$. (a) See text and Table 1 for conditions of thermal and Lewis acid catalysed IMDA; (b) $\mathrm{NaOH}(2 \mathrm{~N}), \mathrm{EtOH}$, $110{ }^{\circ} \mathrm{C}(\mathrm{MW}), 20$ minutes, (71\% for Table 1, entry 3). Crude reaction mixtures analysed by ${ }^{1} \mathrm{H}$ NMR and UPLC. reported to catalyse both intermolecular DA and to a lesser extent IMDA cycloadditions. ${ }^{24-30}$ These reactions are most effective when the dienophile is capable of bidentate coordination to the catalyst as is the case for $5 .^{31}$ Therefore, 5 was stirred for 12 hours $\left(-78{ }^{\circ} \mathrm{C} \rightarrow \mathrm{rt}\right)$ in the presence of either of the bis(oxazoline) metal complexes 11 or 12, or the $\mathrm{Cu}(\mathrm{II})$-sulfinyl imidoamidine (siam) complex 13. Analysis of the crude reaction mixture after ester hydrolysis showed that whilst only moderate control of the $\mathbf{3 a}: \mathbf{3 b}$ ratio was observed, the use of $\mathbf{1 2}$ did result in the formation of natural $\mathbf{3 a}$ in a $3: 2$ ratio compared to $\mathbf{3 b}$ (Table 1 , entry 4). ${ }^{32}$ Further optimisation of reaction conditions is on-going with the goal of converting $\mathbf{5}$ exclusively to $3 \mathbf{a}$.

\section{Conclusions}

The studies reported here provide access to a mixture of the structurally complex and biologically interesting JBIR-22 3a and its diastereomer $\mathbf{3 b}$ in an efficient 8 steps. Furthermore, our results show that a route that involves a late-stage DA cycloaddition in the biosynthesis of JBIR-22 (3) cannot be ruled out. This observation is potentially relevant to other related natural products including equisetin (1) and Sch210972 (4). Further optimisation to enable the selective formation of either $\mathbf{3 a}$ or $\mathbf{3 b}$ is on-going. This will also facilitate access to analogues of JBIR-22 (3) and to other biologically relevant tetramic acid natural products containing diverse decalin rings.

\section{Experimental section}

\section{Materials and methods}

All chemicals and solvents were purchased from Aldrich (UK), Alfa Aesar, or Acros Organics and used without further purification. All reactions involving moisture sensitive reagents were performed in oven or flame dried glassware under a positive pressure of nitrogen. Tetrahydrofuran (THF), dichloromethane (DCM) and hexanes were obtained dry from a solvent purification system (MBraun, SPS-800). Anhydrous $N, N$-dimethylformamide (DMF) was purchased from Aldrich. Thin layer chromatography (TLC) analysis was performed using glass plates coated with silica gel (with fluorescent indicator $\mathrm{UV}_{254}$ ). Developed plates were air dried and analysed under a UV lamp $(254 / 365 \mathrm{~nm})$ or by $\mathrm{KMnO}_{4}$ dip staining. Flash chromatography was performed using silica gel (40-63 $\mu \mathrm{m}$, Fluorochem). Fourier Transform infra-red spectra (FT IR) were acquired on a Shimadzu IRAffinity-1 FT spectrophotometer with a Pike MIRacle $^{\mathrm{TM}}$ (solid or thin film). Absorption maxima are reported in wavenumbers $\left(\mathrm{cm}^{-1}\right)$. Nuclear magnetic resonance (NMR) spectra were recorded at room temperature on Bruker Avance $500\left({ }^{1} \mathrm{H}, 499.9 \mathrm{MHz} ;{ }^{13} \mathrm{C}, 125.7 \mathrm{MHz}\right)$ and Bruker Avance $400\left({ }^{1} \mathrm{H}, 400.1 \mathrm{MHz} ;{ }^{13} \mathrm{C}, 100.6 \mathrm{MHz}\right)$ instruments. NMR spectra were recorded in deuterated solvents and internally referenced to the residual solvent peak, chloroform- $d$ $\left(\delta_{\mathrm{C}} 77.16, \delta_{\mathrm{H}} 7.26 \mathrm{ppm}\right)$ or acetone- $d_{6}\left(\delta_{\mathrm{C}} 29.8, \delta_{\mathrm{H}} 2.04 \mathrm{ppm}\right)$. Chemical shifts are expressed as $\delta$ in units of ppm. ${ }^{13} \mathrm{C}$ NMR 
spectra were recorded using the PENDANT sequence mode. Data processing was carried out using the MestReNova 8.1.1 NMR program (Mestrelab Research S.L.). Low resolution (LR) and high resolution (HR) electrospray mass spectral (ES-MS) analyses were acquired by electrospray ionisation (ESI). Optical rotations were measured on a polarimeter Perkin-Elmer 341 at $20{ }^{\circ} \mathrm{C}$ at a wavelength of $\lambda 589.3 \mathrm{~nm}$ in a $1 \mathrm{~mL}$ quartz cell ( $1 \mathrm{dm}$ length). The concentration is given in $\mathrm{g}$ per $100 \mathrm{~mL}$. The UPLC data was obtained using an Aquity ${ }^{\mathrm{TM}}$ UPLC system.

\section{Representative procedure for the Diels-Alder cyclisation reaction}

To a solution of 5 (1.0 eq.) in DCM at $-78{ }^{\circ} \mathrm{C}$ was added $\mathrm{BF}_{3} \cdot \mathrm{Et}_{2} \mathrm{O}$ (2.0 eq.) or $20 \mathrm{~mol} \% \mathrm{Cu}(\mathrm{II})$-bis(oxazoline) complex (11) ${ }^{29} \mathrm{Mg}(\mathrm{II})$-bis(oxazoline) complex (12) ${ }^{33}$ or $\mathrm{Cu}(\mathrm{II})-\mathrm{siam}$ complex $(13)^{26}$ and the reaction was stirred for 1 hour before slowly warming to room temperature over 11 hours. The reaction was diluted with $\mathrm{H}_{2} \mathrm{O}$ and extracted with DCM. The organic layers were combined, washed with brine, dried over $\mathrm{MgSO}_{4}$, filtered and concentrated in vacuo. Analysis of the crude reaction mixture by ${ }^{1} \mathrm{H}$ NMR was used to confirm completion of the reaction. To a solution of the crude ester in EtOH was added an aqueous solution of $\mathrm{NaOH}(2 \mathrm{~N})$ and the reaction was heated to $110{ }^{\circ} \mathrm{C}$ under microwave irradiation for 20 minutes. A sample of the reaction mixture was analysed directly by UPLC. See indicated references for the preparation of the catalytic complexes.

For experimental details and synthesis of $\mathbf{5}, \mathbf{9}, \mathbf{3} \mathbf{a}$ and $\mathbf{3 b}$ see the ESI. $\dagger$

\section{Acknowledgements}

We would like to thank the following for funding: Cancer Research UK (grants C21383/A6950 and C483/A10706); Dr Rebecca Goss and Duncan Smith for access to and help with UPLC analysis and Carolyn Horsburgh, Tomas Lebl and the EPSRC National Mass Spectrometry Service Centre, Swansea for additional analytical support.

\section{Notes and references}

1 For reviews, see: (a) W. L. Kelly, Org. Biomol. Chem., 2008, 6, 4483-93; (b) E. M. Stocking and R. M. Williams, Angew. Chem., Int. Ed., 2003, 42, 3078-115; (c) H. Oikawa and T. Tokiwano, Nat. Prod. Rep., 2004, 21, 321-52; (d) G. Li, S. Kusari and M. Spiteller, Nat. Prod. Rep., 2014, 31, 11751201.

2 Putative Diels-Alderases include: (a) Solanapyrone synthase H. Oikawa, K. Katayama, Y. Suzuki and A. Ichihara, J. Chem. Soc., Chem. Commun., 1995, 1321-1322; (b) LovB - K. Auclair, A. Sutherland, J. Kennedy, D. J. Witter, J. P. den Heever, C. R. Hutchinson and J. C. Vederas, J. Am. Chem. Soc., 2000, 122, 11519-11520; (c) Macrophomate synthase K. Watanabe, T. Mie, A. Ichihara, H. Oikawa and
M. Honma, J. Biol. Chem., 2000, 275, 38393-38401; (d) Riboflavin synthase - R.-R. Kim, B. Illarionov, M. Joshi, M. Cushman, C. Y. Lee, W. Eisenreich, M. Fischer and A. Bacher, J. Am. Chem. Soc., 2010, 132, 2983-2990; (e) SpnF - H. J. Kim, M. W. Ruszczycky, S. Choi, Y. Liu and H. Liu, Nature, 2011, 473, 109-112; (f) PyrE3/I4 - Z. Tian, P. Sun, Y. Yan, Z. Wu, Q. Zheng, S. Zhou, H. Zhang, F. Yu, X. Jia, D. Chen, A. Mándi, T. Kurtán and W. Liu, Nat. Chem. Biol., 2015, 1-10.

3 (a) K. M. Fisch, RSC Adv., 2013, 3, 18228; (b) H. Wang, D. P. Fewer, L. Holm, L. Rouhiainen and K. Sivonen, Proc. Natl. Acad. Sci. U. S. A., 2014, 111, 9259-9264.

4 Equisetin: isolation - (a) H. R. Burmeister, G. A. Bennett, R. F. Vesonder and C. W. Hesseltine, Antimicrob. Agents Chemother., 1974, 5, 634-639; Biosynthesis - (b) J. W. Sims, J. P. Fillmore, D. D. Warner and E. W. Schmidt, Chem. Commun., 2005, 186-8; (c) T. B. Kakule, D. Sardar, Z. Lin and E. W. Schmidt, ACS Chem. Biol., 2013, 8, 1549-1557; Synthesis - $(d)$ The numbering system used here is based on that of E. Turos, J. Audia and S. Danishefsky, J. Am. Chem. Soc., 1989, 8231-8236; (e) L. T. Burke, D. J. Dixon, S. V. Ley and F. Rodríguez, Org. Lett., 2000, 2, 3611-3613; (f) K. Yuki, M. Shindo and K. Shishido, Tetrahedron Lett., 2001, 42, 2517-2519.

5 C. D. Campbell and J. C. Vederas, Biopolymers, 2010, 93, 755-63.

6 S. M. Ma, J. W.-H. Li, J. W. Choi, H. Zhou, K. K. M. Lee, V. a. Moorthie, X. Xie, J. T. Kealey, N. a. Da Silva, J. C. Vederas and Y. Tang, Science, 2009, 326, 589-92.

7 J. Yin, C. Wang, L. Kong, S. Cai and S. Gao, Angew. Chem., Int. Ed., 2012, 51, 7786-7789.

8 J. Xu, E. J. E. Caro-Diaz, L. Trzoss and E. a. Theodorakis, J. Am. Chem. Soc., 2012, 134, 5072-5.

9 J. Yin, L. Kong, C. Wang, Y. Shi, S. Cai and S. Gao, Chem. Eur. J., 2013, 19, 13040-13046.

10 J. Deng, B. Zhu, Z. Lu, H. Yu and A. Li, J. Am. Chem. Soc., 2012, 134, 920-923.

11 M. Izumikawa, J. Hashimoto, T. Hirokawa, S. Sugimoto, T. Kato, M. Takagi and K. Shin-Ya, J. Nat. Prod., 2010, 73, 628-31.

12 J. Hashimoto, T. Watanabe, T. Seki, S. Karasawa, M. Izumikawa, T. Seki, S.-I. Iemura, T. Natsume, N. Nomura, N. Goshima, A. Miyawaki, M. Takagi and K. Shin-Ya, J. Biomol. Screen., 2009, 14, 970-9.

13 A. R. Healy, M. Izumikawa, A. M. Z. Slawin, K. Shin-ya and N. J. Westwood, Angew. Chem., Int. Ed., 2015, 54, 40464050.

14 F. Vinale, M. Nigro, K. Sivasithamparam, G. Flematti, E. L. Ghisalberti, M. Ruocco, R. Varlese, R. Marra, S. Lanzuise, A. Eid, S. L. Woo and M. Lorito, FEMS Microbiol. Lett., 2013, 347, 123-129.

15 A. R. Healy, F. Vinale, M. Lorito and N. J. Westwood, Org. Lett., 2015, 17, 692-695.

16 S. Yang, R. Mierzwa, J. Terracciano, M. Patel, V. Gullo, N. Wagner, B. Baroudy, M. Puar, T. Chan and M. Chu, J. Antibiot., 2007, 60, 524-528. 
17 S.-W. Yang, R. Mierzwa, J. Terracciano, M. Patel, V. Gullo, N. Wagner, B. Baroudy, M. Puar, T.-M. Chan, A. T. McPhail and M. Chu, J. Nat. Prod., 2006, 69, 1025-8.

18 (a) K. Watanabe, Chem. Pharm. Bull., 2014, 62, 1153-1165; (b) T. B. Kakule, S. Zhang, J. Zhan and E. W. Schmidt, Org. Lett., 2015, 17, 2295-2297.

19 B. B. Snider and Q. Lu, J. Org. Chem., 1996, 61, 2839-2844.

20 For a related one-pot Dieckmann-olefination process in the total synthesis of streptolydigin, see: S. V. Pronin and S. A. Kozmin, J. Am. Chem. Soc., 2010, 132, 14394-14396; and in the total synthesis of $\beta$-lipomycin, see: O. Hartmann and M. Kalesse, Angew. Chem., Int. Ed., 2014, 53, 7335-7338.

21 For a synthetic study of the viability and rate of the proposed IMDA cycloaddition in the biosynthesis of USC1025A, see: T. R. Hoye and V. Dvornikovs, J. Am. Chem. Soc., 2006, 128, 2550-2551.

22 See ESI of ref. 13 for synthesis.

23 Endo selectivity of the IMDA cycloaddition determined by ${ }^{1} \mathrm{H}$ NMR comparison with the authentic samples of $\mathbf{3 a}$ and $\mathbf{3 b}$.

24 D. A. Evans, D. M. Barnes, J. S. Johnson, T. Lectka, P. Von Matt, S. J. Miller, J. A. Murry, R. D. Norcross, E. A. Shaughnessy and K. R. Campos, J. Am. Chem. Soc., 1999, 7582-7594.

25 G. Desimoni, G. Faita and K. A. Jørgensen, Chem. Rev., 2006, 106, 3561-651.
26 T. Owens, F. Hollander, A. Oliver and J. Ellman, J. Am. Chem. Soc., 2001, 123, 1539-1540.

27 K. Takao, R. Munakata and K. Tadano, Chem. Rev., 2005, 105, 4779-4807.

28 N. Iwasawa, J. Sugimori, Y. Kawase and K. Narasaka, Chem. Lett., 1989, 18, 1947-1950.

29 D. Evans and J. Johnson, J. Org. Chem., 1997, 62, 786787.

30 D. Evans, S. Miller, T. Lectka and P. von Matt, J. Am. Chem. Soc., 1999, 121, 7559-7573.

31 For a discussion of metal chelation by 3-acyltetramic acids, see: (a) B. J. L. Royles, Chem. Rev., 1995, 95, 1981-2001; (b) R. Schobert and A. Schlenk, Bioorg. Med. Chem., 2008, 16, 4203-21; (c) G. Athanasellis, O. Igglessi-Markopoulou and J. Markopoulos, Bioinorg. Chem. Appl., 2010, 2010, 315056.

32 The attempted catalysed IMDA reaction of substrate $\mathbf{5}$ in the presence of catalyst $\mathbf{1 1}$ or $\mathbf{1 3}$ gave either in the case of 11 no enrichment in $\mathbf{3 a}$ (ratio of $\mathbf{3 a}: \mathbf{3} \mathbf{b} 1: 1$ ) or in the case of 13 an analogous result to 12 (ratio of $3 \mathbf{a}: \mathbf{3 b} 3: 2$ ). In both case the analytical UPLC analysis led to less complete separation of the peaks (data not shown) and hence these values are subject to a larger errors than in the case of $\mathbf{1 2}$ (see Fig. $\mathrm{S} 1 \dagger$ ).

33 E. Corey and K. Ishihara, Tetrahedron Lett., 1992, 33, 68076810 . 